\title{
FATIGUE LIFE ESTIMATION OF HYBRID ALUMINIUM MATRIX COMPOSITES
}

\author{
Achutha M.V., Sridhara B.K. ${ }^{2}$, Abdul Budan ${ }^{3}$ \\ ${ }^{1,2}$ Department of Mechanical Engineering, National Institute of Engineering, Mysore, Karnataka, India. \\ ${ }^{3}$ Department of Mechanical Engineering, UBDT College of Engineering, Davangere, Karnataka, India. \\ E-mail: 1mvachutha@yahoo.co.in
}

\begin{abstract}
The fatigue and mechanical properties of composite consisting of AA 6061(LM 25) Aluminium alloy reinforced with silicon carbide and graphite particles were investigated with the primary objective of understanding the influence of the particulate reinforcement on the fatigue and mechanical behavior of the LM 25 Aluminium alloy. The combined silicon carbide and graphite content in the hybrid composite was $2.5 \mathrm{wt} \%$. The composite was fabricated by gravity die casting technique in which the reinforcement particles were dispersed in the vortex created in the molten matrix alloy. Statistical design of experiments was applied to carry out fatigue tests on rotating beam fatigue testing machine under stress controlled conditions. Three different stress levels at $0.9 \mathrm{Su}, 0.7 \mathrm{Su}$ and $0.5 \mathrm{Su}$ where Su=Ultimate Strength of the Composite were used. For the hybrid Al-SiC-Gr composite, improvements in Young's modulus, ultimate tensile strength (UTS), compressive strength, yield strength and hardness was observed but at the expense of ductility. Fatigue data exhibited large scatter. Monte Carlo Simulation model was developed. The Simulated fatigue data and the experimental data were compared and validated. The Simulated model helps designers to obtain accurate fatigue data without conducting large number of time consuming fatigue experiments.
\end{abstract}

Key words: Hybrid metal matrix composites, Monte Carlo Simulation, Fatigue

\section{INTRODUCTION}

The presence of reinforcements, such as Silicon Carbide(SiC) in the Aluminium alloy matrix increases the mechanical properties and the load carrying capability[1]. T.J.A.Doel and P.Bowen[2] have reported the tensile behavior of $\mathrm{SiC}$ particulate reinforced Composite depends on particle size, and ageing conditions. Lin C.B, Chang R.J and Weng W.P[3] have reported the incorporation of the reinforcements in aluminium alloy matrix, such as graphite particles provide improved tribological properties. However, as the volume fraction of the graphite particles in the composite increases, its mechanical properties decrease[4]. The addition of graphite particles to aluminium alloys improves sliding wear and seizure resistance compared to non-reinforced aluminium alloys. Since graphite particles are lighter than matrix metallic alloys, aluminium graphite composites are used to reduce the weight of components[5]. Recent advances in the technology of automotive engines have generated the need to develop new materials for better antifriction and wear performance on specific components like piston, cylinder blocks or liners, connecting rods, various types of brakes, air diffusers and bushings. For bearing application, the aluminium-graphite composite save considerably in cost and weight and has the added benefit of being self-lubricating[6].

Cevdet Kaynak and Suha Boylu[7] investigated the effects of SiC particulates on the fatigue behaviour of $\mathrm{Al}$ alloy matrix composite. They found the improvement in fatigue resistance with increasing content of SiC particulates upto $15 \mathrm{wt} \%$. Researchers T.S.Srivatsan etal. studied the fracture morphology of SiC particulate reinforcement phase in the 6061 aluminium alloy metal matrix. With the increase in $\mathrm{SiC}$ contents in the metal matrix, fractures of the composite were dominated by particulate cracking and decohesion at the particulatematrix interface [8].

Little [9] discussed the methods of fatigue testing in design of fatigue experiments, planning of test program and common methods of fatigue data analysis. Lipson and Sheth[10] have given the procedure for selection of stress levels, sample size determination and determination of average fatigue life.

A combination of soft lubricant like graphite and hard reinforcements like $\mathrm{SiC}$ can improve the tribological properties of the composite and strength more than the properties of composites containing either $\mathrm{SiC}$ or graphite particles by themselves. Composites containing more than one type of reinforcements are called hybrid composites. Such composites by using two or more types of reinforcements extend the idea of tailor-making a composite material to meet specific property requirement. In addition, since graphite particles are lighter than the matrix metallic alloys, the hybrid composite can be used to reduce the weight more than the Al-SiC composite.

Recently there are attempts to use hybrid composites as bearing materials, which are prone to surface fatigue 
wear. Reasonably good amount of data is available on

Mechanical and fatigue properties of $\mathrm{Al}-\mathrm{SiC}$ and Al$\mathrm{Gr}$ Composites. However, work related to fatigue characterization of Hybrid Al-SiC-Gr Composites is limited. . Thus, there is a need to establish fatigue properties of Aluminium matrix hybrid composites.

\section{EXPERIMENTS}

The procedure to establish S-N Curve is as follows:

a. Static tests to determine the ultimate tensile strength.

b. Selecting the stress level.

c. Determination of sample size.

d. Conduct of tests.

e. Analysis and presentation of data.

The Hybrid Al-SiC-Graphite composites specimens were cast by liquid metallurgy technique using aluminium alloy AA6061 (LM 25) as the matrix and containing 2.5\% combined weight percentages of silicon carbide ( $\mathrm{SiC}$ ) particles of $10 \mu$ size and Graphite of $74 \mu$ size. The LM25 specimens were also cast without any reinforcements. Table 1 shows the chemical composition of matrix aluminium alloy. Tests were carried out to determine the mechanical properties of the LM 25 and $2.5 \mathrm{wt} \%$ hybrid AlSiC-Gr composite. Fig. 1 shows the standard tensile test specimen details.

Table 1. Chemical composition of the matrix alloy LM25

\begin{tabular}{|ccccccccc|}
\hline Element & $\mathrm{Si} \%$ & $\mathrm{Mg} \%$ & $\mathrm{Fe} \%$ & $\mathrm{Cu} \%$ & $\mathrm{Mn} \%$ & $\mathrm{Ni} \%$ & $\mathrm{Zn} \%$ & $\mathrm{Cr} \%$ \\
\hline Content & 7.14 & 0.312 & 0.32 & $<0.012$ & 0.281 & 0.010 & 0.002 & 0.004 \\
\hline
\end{tabular}

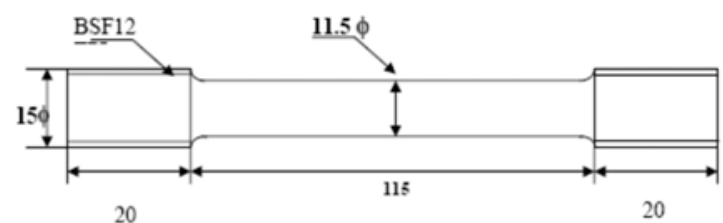

Fig. 1. Tensile Test Specimen

Table 2 and 3 shows the Mechanical Properties of LM25 alloy and 2.5wt\% Hybrid Al-SiC-Gr Composite. For the $2.5 \mathrm{wt} \%$ Hybrid Al-Si-Gr composite, the Ultimate tensile strength and the yield strength increases. The increase in UTS and Yield Strength can be attributed to the presence of hard SiC particles which impart strength to the LM 25 matrix, bestowing more resistance to the composite against the applied tensile stresses. This increase in UTS and yield strength is consistent with the results obtained by another investigator McDaneals[11] who tested SiC particles reinforced MMCs with various alloy matrices.

Table 2. Average values of Mechanical Properties of LM 25 pure alloy

\begin{tabular}{|ccccc|}
\hline $\begin{array}{c}\text { Ultimate } \\
\text { Tensile } \\
\text { Strength } \\
\text { In MPa }\end{array}$ & $\begin{array}{c}\text { Yield } \\
\text { Strength } \\
\text { in } \mathrm{MPa}\end{array}$ & $\begin{array}{c}\text { Modulus of } \\
\text { Elasticity } \\
\text { In GPa }\end{array}$ & $\begin{array}{c}\text { Hardness } \\
(\mathrm{BHN})\end{array}$ & $\begin{array}{c}\text { Ductility } \\
\text { (\%Elongation) }\end{array}$ \\
\hline 135 & 48.92 & 89 & 67.02 & 3.04 \\
\hline
\end{tabular}

Table 3. Mechanical Properties for $2.5 w t \%$ Hybrid Al-SiC-Gr Composite.

\begin{tabular}{|cccccc|}
\hline \% SiC+\%Gr & $\begin{array}{c}\text { Ultimate Tensile } \\
\text { Strength in } \mathrm{MPa}\end{array}$ & $\begin{array}{c}\text { Yield Strength } \\
\text { in MPa }\end{array}$ & $\begin{array}{c}\text { Modulus of } \\
\text { Elasticity in } \mathrm{GPa}\end{array}$ & $\begin{array}{c}\text { Hardness } \\
\text { in } \mathrm{BHN}\end{array}$ & $\begin{array}{c}\text { Ductility } \\
\text { in \% }\end{array}$ \\
\hline 2.5 & 140 & 52 & 68 & 71.66 & 1.5 \\
\hline
\end{tabular}

\section{A. Microstructure characterization}

Fracture surfaces of the tensile failed specimens were comprehensively examined in a CARL JOEL scanning electron microscope. The microstructure of the 2.5\% Hybrid Al-SiC-Gr composite tensile fracture surface with tear ridges is shown in the Fig. 2. and with microscopic voids, crack and cracked particulates is shown in the Fig. 3. The discontinuous $\mathrm{SiC}$ and $\mathrm{Gr}$ particulate reinforcement phase in the 6061 aluminium alloy matrix, were of non-uniform size, irregularly shaped and dispersed randomly through the alloy matrix. At frequent intervals an agglomeration or clustering of the $\mathrm{SiC}$ and $\mathrm{Gr}$ reinforcements was observed resulting in particulate-rich and particulate-depleted regions. A nonuniform distribution of the reinforcing $\mathrm{SiC}$ and $\mathrm{Gr}$ particulates in the aluminium alloy matrix results in an anisotropic microstructure of the Hybrid composite. Observation of the tensile fracture specimen revealed the presence of microscopic voids in the matrix of the composite. Few of the microscopic voids were intermingled with tear ridges and isolated pockets of dimple.

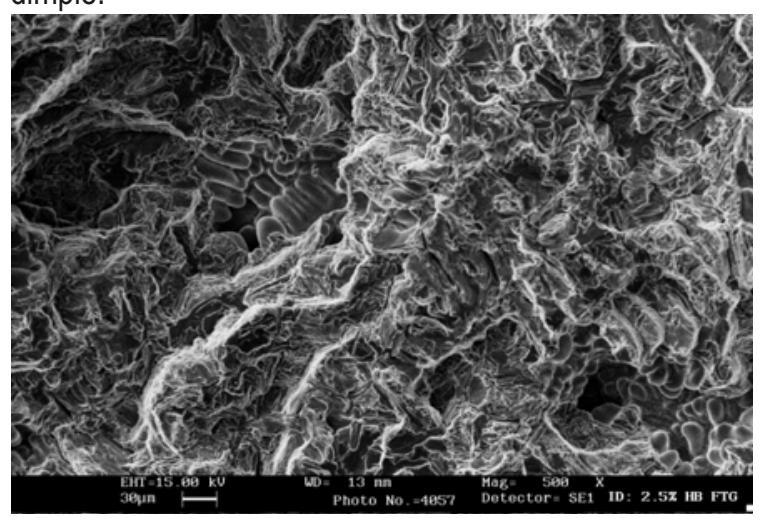

Fig. 2. Scanning electron micrograph of tensile fracture surface of $2.5 \%$ Hybrid Al-SiC-Gr composite showing tear ridges. 


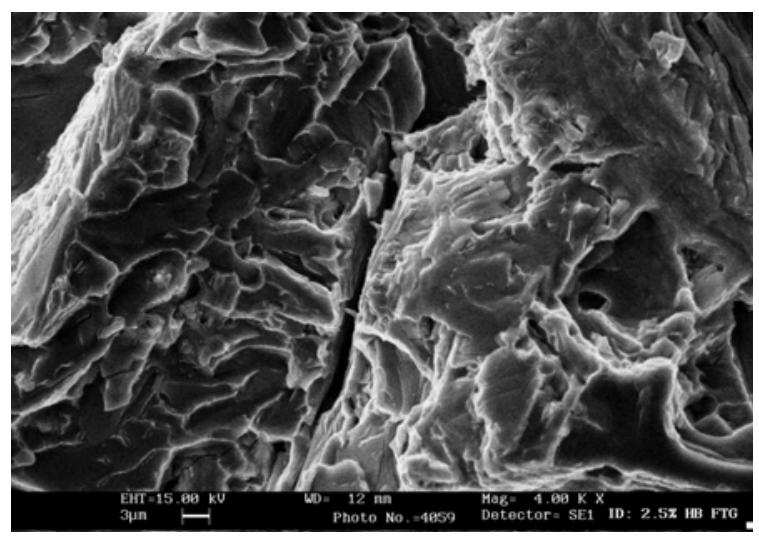

Fig. 3. Scanning electron micrograph of tensile fracture surface of the of $2.5 \%$ Hybrid Al-SiC-Gr composite showing microscopic voids, crack and cracked particulates.

\section{B. Sample size determination}

Statistical design of experiments was carried out to determine the correct sample size.

The relationship between specimen allocated, percent error that can be tolerated, confidence level and the expected variation in the fatigue life can be determined by the following methodology.

Percent error is defined as the error made when the sample average $x_{1}$ is accepted to be the population log mean $\mu_{1}$.

Percent Error is given by $=$

$$
\pm\left[\frac{s_{1} t \alpha / 2 ; v}{\bar{X}_{l} \sqrt{n}}\right]
$$

$x_{1}$ is the sample log average life, equal to

$$
\left[\sum_{i=}^{n} \frac{\left(x_{1}\right)_{i}}{n}\right]
$$

$n=$ sample size

$v=$ degree of freedom $(\mathrm{n}-1)$

$\alpha / 2=$ degree of confidence, where confidence is equal to $(1-a)$

$S_{1}=$ sample log standard deviation of life is given by;

$\mathrm{S}_{1}=\left[\sum_{i=}^{n} \frac{\left(x_{1}-\bar{x}_{j}\right)^{2}}{n-1}\right]^{1 / 2}$
Fig. 4 shows the standard fatigue test specimen details. The ratio of percent error to coefficient of variation when plotted against sample size at different confidence levels, a plot as shown in Fig 5 can be obtained from which sample size at different stress levels can be determined. Since fatigue testing is time consuming it is generally recommended to conduct tests at 3 or 5 levels $[12,13$, and 14]. In this investigation it was chosen to use three-stress level fatigue test program. The tests were conducted at Level I $\left(0.9 \mathrm{~S}_{u}\right)$, Level II $\left(0.7 \mathrm{~S}_{u}\right)$, Level III $\left(0.5 \mathrm{~S}_{u}\right)$ (where $\mathrm{S}_{u}$ is the Ultimate Tensile Strength.[9]

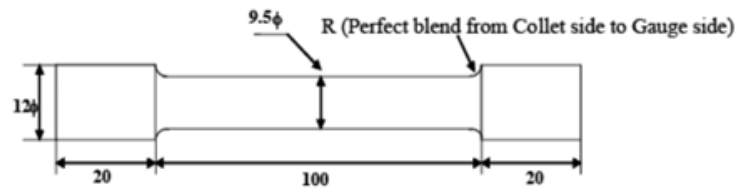

Fig. 4. Fatigue Testing Specimen

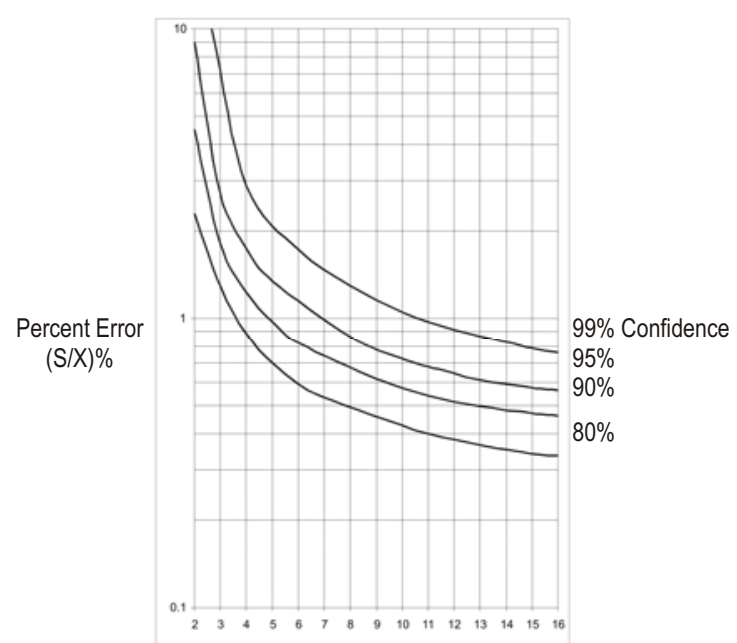

Fig. 5. Sample size determination for estimating average fatigue life [10]

The sample size at each stress level was determined at confidence level of $90 \%$ based on the following assumptions.

1) Scatter in fatigue lives is not uniform at all stress levels, 2) Percent error of $10 \%$ is tolerable and 3) Coefficient of variation (C.O.V) of fatigue lives at level I = $4 \%$, level $I I=5 \%$ and at level $I I I=7 \%$. The assumption 3 is only tentative. In the event that variation of fatigue life is more than the assumed at a given stress level, additional specimens can be tested in order to maintain the same percent error and confidence at all three stress levels. Table 4 shows the required sample size for $10 \%$ error and 90\% Confidence for 2.5\% HybridAl-SiC-Gr Composite.

$t_{/ 2 ; \mathrm{v}}=$ value of $\mathrm{t}$ statistics, available in standard tables. 
Table 4. Required Sample Size for $10 \%$ error and 90\% Confidence for $2.5 \%$ Hybrid Composites

\begin{tabular}{|cccc|}
\hline Stress(MPa) & $\begin{array}{c}\text { Assumed } \\
\text { C.O.V.(\%) }\end{array}$ & $\begin{array}{c}\text { \% Error / Assumed C.O.V } \\
(\%)\end{array}$ & $\begin{array}{c}\text { Required sample } \\
\text { size }\end{array}$ \\
\hline $126(0.9 \mathrm{Su})$ & 4 & 2.5 & 3 \\
$98(0.7 \mathrm{Su})$ & 5 & 2 & 3 \\
$70(0.5 \mathrm{Su})$ & 7 & 1.43 & 4 \\
\hline
\end{tabular}

\section{Determination of average fatigue life}

Experiments were conducted at three different stress levels. The number of test specimens to be tested at each stress level was determined using Fig. 5. The number of cycles of rotation corresponding to the specimen failure is noted down and is considered as the fatigue life of the specimen. The average speed of rotation was around $2000 \mathrm{rpm}$. The tests were conducted in a random order to minimize the effect of uncontrollable variables.

\section{$D$. Analysis of fatigue results}

Table 5 shows the analysis of Test Results to determine Average Fatigue Life within 10\% Error and 90\% confidence according to initial estimate for 2.5\% Hybrid composite. Table 6 shows the revised Test Plan for $2.5 \%$ Hybrid Composites. The actual COV is less than the assumed value. From the Graph of fig 5 , It is clear that 3 samples are sufficient, however 11 more samples were tested, so that totally 14 specimens were tested in all the three stress levels to determine the scatter accurately.

Table 5. Analysis of Test Results to determine Average Fatigue Life within 10\% Error and $90 \%$ confidence according to initial estimate for $2.5 \%$ Hybrid composite.

\begin{tabular}{|c|c|c|c|c|c|c|}
\hline Sample & Stress LevelI & $126 \mathrm{MPa}$ & Stress Level II & $98 \mathrm{MPa}$ & Stress Level & $70 \mathrm{MPa}$ \\
\hline Number & & & & \multicolumn{3}{|c|}{ III } \\
\hline & Lise (Cydes) & $\log ($ Life) & Lfe (Cycles) & $\log (L f e)$ & Life (Cydes) & Log (Ule) \\
\hline 1 & 182362 & 5.2609 & 1037655 & 6.0160 & 1338256 & 6.1265 \\
\hline 2 & 375654 & 5.5747 & 380876 & 5.5807 & 811226 & 5.9091 \\
\hline 3 & 204517 & 5.3107 & 610073 & 5.7853 & 667849 & 5.8246 \\
\hline 4 & & & & & 728114 & 5.8621 \\
\hline Average & 254178 & 5.3821 & 676201 & 5.794 & 886361 & 59306 \\
\hline Standard & \multicolumn{2}{|c|}{0.1686} & \multicolumn{2}{|c|}{0.218} & \multicolumn{2}{|c|}{0.1351} \\
\hline \multicolumn{7}{|l|}{ Deviation } \\
\hline$\%$ c.o.v & \multicolumn{2}{|c|}{3.13} & \multicolumn{2}{|c|}{3.76} & \multicolumn{2}{|c|}{228} \\
\hline
\end{tabular}

Table 6. Revised Test Plan for $2.5 \%$ Hybrid Composite

\begin{tabular}{|cccc|}
\hline Stress(MPa) & $\begin{array}{c}\text { Actual C.O.V. } \\
(\%)\end{array}$ & $\begin{array}{c}\text { \% Error / Actual C. . . V } \\
(\%)\end{array}$ & Actual sample size \\
\hline 126 & 3.13 & 3.194 & 14 \\
98 & 3.76 & 2.659 & 14 \\
70 & 2.28 & 4.385 & 14 \\
\hline
\end{tabular}

Large number of specimens is required to be tested at each level to determine the wide scatter. Reference 10 gives the guidelines for the sample size requirement based on minimum percentage replication as given in table 7 .

Table 7. Guidelines for Replication and sample size in stress life testing[10]

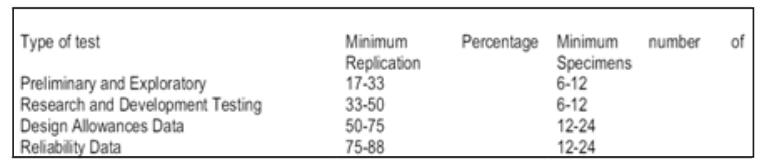

Percentage replication is the portion of total number of specimens that may be used for obtaining an estimate of variability of replicate tests. The percentage replication was calculated as:

Percentage Replication $=100[1-(T L / T N)]$

Where

$T L=$ Total number of different stress levels used in testing $=3$

$\mathrm{TN}=$ Total number of specimens tested $=3$ stress levels $\times 14$ specimens $=48$

Replication percentage $=[1-(3 / 48)]^{*} 100$

$=94 \%$ which agrees with the values given in Table 7.

Table 8 shows the results of Revised Sample Size $=14$, for $2.5 \%$ Hybrid Composite.

Table 8. Results of fatigue failure of Revised Sample Size $=14$, for $2.5 \%$ Hybrid Composites

\begin{tabular}{|c|c|c|c|c|c|c|}
\hline \multirow[b]{2}{*}{$\begin{array}{l}\text { Sample } \\
\text { Number }\end{array}$} & \multicolumn{2}{|c|}{ Stress level-I(126MPa) } & \multicolumn{2}{|c|}{ Stress level-11(9eMPa) } & \multicolumn{2}{|c|}{ Stress level-Hil(70Mpa) } \\
\hline & Life(Cydes) & $\log (\mathrm{L}$ ife $)$ & Lfe (Cycles) & $\log (\mathrm{L} / \mathrm{e})$ & Life (Cycles) & $\log$ (Life) \\
\hline 1 & 182362 & 5.2609 & 1037655 & 6.0160 & 1338256 & 6.1265 \\
\hline 2 & 375654 & 5.5747 & 380876 & 5.5807 & 811226 & 5.9091 \\
\hline 3 & 204517 & 5.3107 & 610073 & 5.7853 & 667849 & 5.8246 \\
\hline 4 & 8694 & 3.9392 & 154549 & 5.1890 & 728114 & 5.8621 \\
\hline 5 & 194833 & 5.2896 & 886413 & 5.9476 & 24475 & 4.3887 \\
\hline 6 & 644217 & 5.8090 & 745384 & 5.8723 & 554713 & 5.7440 \\
\hline 7 & 13085 & 4.1167 & 19864 & 4.2980 & 1025416 & 6.0109 \\
\hline 8 & 381152 & 5.5810 & 1285218 & 6.1089 & 65434 & 4.8158 \\
\hline 9 & 385473 & 5.5859 & 276480 & 5.4416 & 345477 & 5.5384 \\
\hline 10 & 676394 & 5.8301 & 433129 & 5.6366 & 476543 & 5.6781 \\
\hline 11 & 495815 & 5.6953 & 547718 & 6.7385 & 934994 & 5.9708 \\
\hline 12 & 70334 & 4.8471 & 752667 & 5.8766 & 1167883 & 6.0673 \\
\hline 13 & 112422 & 5.0508 & 47369 & 4.6754 & 872913 & 5.9409 \\
\hline 14 & 191176 & 5.2814 & 457981 & 5.6608 & 1096695 & 6.0400 \\
\hline Average & 281152 & 5.4489 & 545384 & 5.7367 & 722142 & 5.8586 \\
\hline
\end{tabular}


Fig. 6 shows S-N curve comparison of $2.5 w t \%$ Hybrid Al-SiC-Gr Composite and base Alloy LM25. The fatigue resistance of Hybrid Al-SiC-Gr composite is superior to that of the matrix alloy.

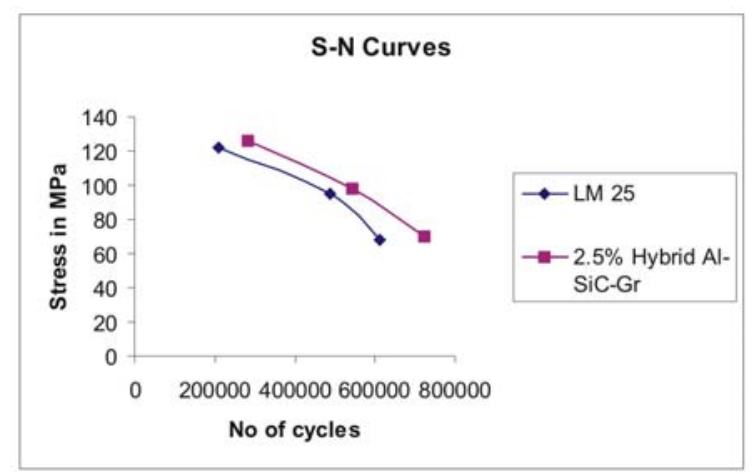

Fig. 6. Comparison of Fatigue Bheavior of 2.5wt\%Hybrid A1-SIC-Gr Composite with base Alloy LM25.

\section{MONTE CARLO SIMULATION}

Monte Carlo method is a computational algorithm that relies on repeated random sampling to compute results. Monte Carlo methods are often used when simulating physical and mathematical systems. Because of their reliance on repeated computation and random or pseudo-random numbers, Monte Carlo methods are most suited to calculation by a computer. Monte Carlo methods tend to be used when it is infeasible or impossible to compute an exact result with a deterministic algorithm.

The term Monte Carlo was coined in the 1940s by physicists working on nuclear weapon projects in the Los Alamos National Laboratory. Essentially, the Monte Carlo method is a sophisticated means of randomly selecting a sample from one distribution and comparing it with a sample taken from a different distribution.

N. Metropolis and S. Ulam[15] have given the fundamentals of Monte Carlo method. Fishman, G.S. [16] have discussed the detailed Concepts, Algorithms, and Applications of Monte Carlo methods. D. Kahneman and A. Tversky [17] have given the detailed procedure to apply Monte Carlo method during situations of uncertainty. R. E. Caflisch [18] analyzed the correct procedure for the application of Monte Carlo methods.

There are many situations where the probability of occurrence of a random variable is not constant, as in the case of fatigue data which generally follow log normal distribution or weibull distribution. The fatigue data exhibit large scatter. Work related to development of a simulation model for Hybrid composites is limited.

The laborious problem of carrying out a large number of fatigue experiments to determine the scatter can be avoided by this fatigue simulation model.

\section{A. Procedure for Monte Carlo Simulation of Fatigue Data Using EXCEL}

a) Determine the experimental fatigue values.

b) Determine the Average and Std. Deviation of the experimental fatigue values.

c) If $P(x)$ is the probability of failure at a particular lifecycle, then random number denotes its occurrence.

d) Formulate a mathematical relationship to simulate values to the left and right of the mean value as shown in Fig. 7.

e) For the values to the left of the mean, the relationship is LF1=Avg - (Std.Dev * Random number)

f) For the values to the right of the mean, the relationship is

$$
\mathrm{LF} 2=A v g+(\text { Std.Dev * Random number })
$$

g) Use the above relationship and generate random fatigue lives using Excel.

h) Verify the best distribution of the simulated values i.e., Lognormal or Weibull distribution by determining Anderson Darling Coefficient and Correlation Coefficient.

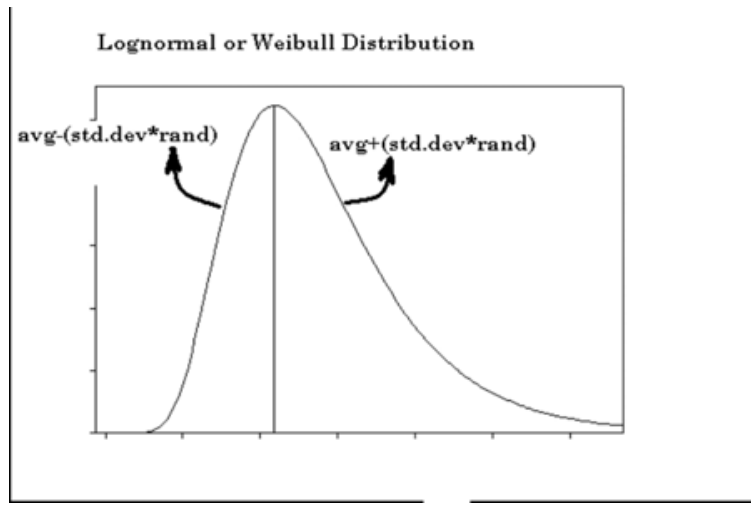

Fig. 7. Mathematical relationship for the simulated values for Monte Carlo Simulation of Fatigue Data Using EXCEL.

\section{B. Procedure for Monte Carlo Simulation of Fatigue Data Using MATLAB}

A suitable software is developed to simulate fatigue lives using MATLAB. Using the software developed the fatigue lives are simulated at different stress levels and these values are compared with the experimental values.

\section{Analysis of Monte Carlo Simulation results}

Comparison of experimental fatigue values with Monte Carlo simulated values for $2.5 \%$ Hybrid composite 
at stress level-1 is given in Table 9. The average experimental fatigue values and the Monte Carlo simulated fatigue values are same. The probability distribution plot to determine goodness of fit for $2.5 \%$ Hybrid composite at stress level-1 for experimental fatigue values is given in Fig. 8. Monte Carlo simulated fatigue lives using EXCEL is given in Fig. 9 and Monte Carlo simulated fatigue lives using MATLAB is given in Fig. 10. The comparison of probability distribution parameters for $2.5 \%$ Hybrid Composite at stress level- 1 for Experimental fatigue lives, Monte Carlo Simulated fatigue lives using EXCEL and Monte Carlo simulated fatigue lives using MATLAB is given in Table 10.

Table 9. Comparison of Experimental Fatigue values with Monte Carlo Simulated Values for 2.5\% Hybrid Composite at Strees Level - I

\begin{tabular}{|cccc|}
\hline Sample Number & Experimental Values & $\begin{array}{c}\text { Monte-Carlo Simulated - Monte-Carlo Simulated- } \\
\text { EXCEL. } \\
\text { MATLAB }\end{array}$ & \\
\hline 1 & & 52140 & 6012 \\
2 & 8694 & 117615 & 8062 \\
3 & 13085 & 162789 & 11054 \\
4 & 70334 & 166903 & 15699 \\
5 & 112422 & 173985 & 22485 \\
6 & 182362 & 200410 & 22623 \\
7 & 191176 & 233456 & 33950 \\
8 & 194833 & 328847 & 53164 \\
9 & 204517 & 361893 & 87123 \\
10 & 375654 & 395400 & 153350 \\
11 & 381152 & 388318 & 293100 \\
12 & 385473 & 399514 & 639608 \\
13 & 495815 & 444688 & 961226 \\
14 & 644217 & 510163 & 1628672 \\
Average & 676394 & 281152 & 281152 \\
\hline
\end{tabular}

Table 10. Comparison of Probability Distribution Parameters for $2.5 \%$ Hybrid Composite at Stress Level-I

\begin{tabular}{|c|c|c|c|c|c|c|}
\hline \multicolumn{2}{|c|}{$\begin{array}{c}\text { Anderson-Dading C } \\
\text { Coefficient }\end{array}$} & \multicolumn{2}{|c|}{ Correlation-Coefficient M } & \multicolumn{3}{|c|}{$\begin{array}{l}\text { Mean Time To Failure } \\
\text { (MTTF-Cycles) }\end{array}$} \\
\hline \multirow[b]{2}{*}{ Experimental } & Lognomal & \multirow{2}{*}{$\begin{array}{l}\text { al Weibull } \\
1.654\end{array}$} & \multirow{2}{*}{$\begin{array}{l}\text { Lognomal } \\
0.964\end{array}$} & \multicolumn{2}{|c|}{ Weibull Lognormal } & \\
\hline & 1.227 & & & 0.920 & 325827 & 401816 \\
\hline Monte Carlo(EXCEL) & 1.163 & 1.348 & 0.980 & 0.947 & 286189 & 296548 \\
\hline $\begin{array}{l}\text { Monte } \\
\text { Carlo(MATLAB) }\end{array}$ & 1.891 & 1.142 & 0.933 & 0.976 & 194892 & 420237 \\
\hline
\end{tabular}

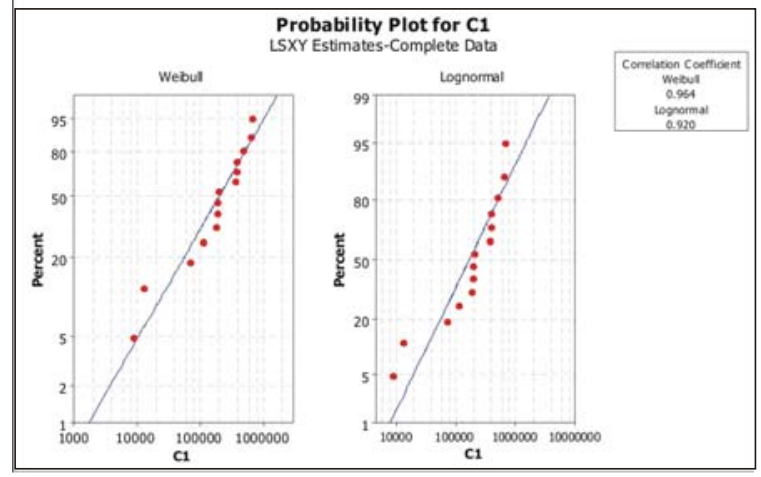

Fig. 8. Probability Distribution Plot for $2.5 \%$ Hybrid Composite Stress Level-I(Experimental)

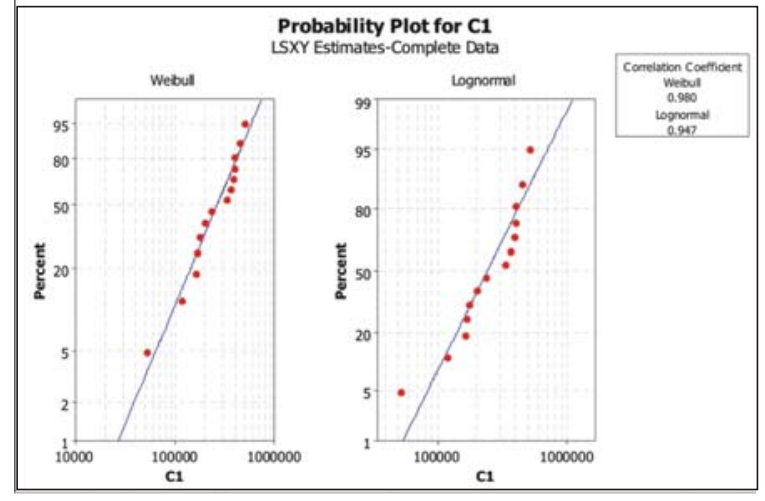

Fig. 9. Probability Distribution Plot for $2.5 \%$ Hybrid Composite at Stress Level-I(Monte Carlo Simulated-EXCEL)

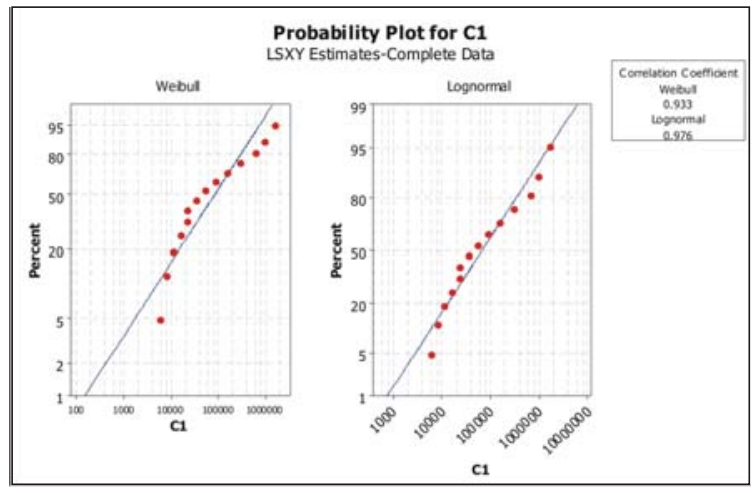

Fig. 10. Probability Distribution Plot for $2.5 \%$ Hybrid Composite Stress Level-I(Monte Carlo Simulated-MATLAB)

Anderson-Darling Coefficient is a measure of how far the plot points fall from the fitted line in a probability plot. A smaller Anderson-Darling Coefficient indicates that the distribution fits the data better [19] whereas a higher Correlation Coefficient indicates that the distribution fits the data better. It is clear from the Table 10 that for experimental fatigue values, the Anderson Darling Coefficient is lower for weibull distribution and Correlation Coefficient is higher. For Monte Carlo simulated fatigue 
lives using EXCEL also weibull distribution is the best fit. However for Monte Carlo simulated fatigue lives using MATLAB, lognormal distribution is the best fit.

The comparison of Mean Time to Failure (MTTF) for the experimental fatigue lives and the Monte Carlo simulated fatigue lives using EXCEL and MATLAB is also given in Table 10. MTTF between Monte Carlo (EXCEL) and Experimental values for weibull distribution exhibited less deviation. However, MTTF between Monte carlo(MATLAB) and Experimental values for lognormal distribution, exhibited less deviation. Therefore, for weibull distribution, Monte Carlo(EXCEL) is more suitable and for log normal distribution, Monte Carlo(MATLAB) is preferable.

\section{CONCLUSION}

Fatigue lives for $2.5 \mathrm{wt} \%$ Hybrid Al-SiC-Gr composite is determined experimentally at different stress levels and compared with the base alloy LM 25. Hybrid composite showed an improvement in the fatigue resistance compared to base alloy LM 25. The fatigue data exhibited large scatter. A large number of experiments need to be conducted to determine the scatter. Monte Carlo simulation fatigue life estimation model was developed to simulate fatigue lives. The Comparison of experimentally determined and Monte Carlo simulated average fatigue lives showed they are the same. The Comparison of probability distribution parameters using AndersonDarling Coefficient and Correlation Coefficient helped in selecting the best fit. The tedious job of conducting large number of experiments can be avoided by using this simulation model.

\section{REFERENCES}

[1] Jody N.Hall., J.Wayne Jones., Anil K. Sachdev., Particle Size, Volume fraction and matrix strength effects on fatigue behavior and particle in 2124 aluminium-SiCp Composites, Elsevier, Materials Science and Engineering, 1994, A183 :69-80.

[2] Doel T.J.A and Bowen P, Tensile properties of particulate reinforced metal matrix composites, Elsevier, Composites Part-A, 27A, 1996, 655665.

[3] Lin CB, Chang RJ, Weng WP. Astudy on process and tribological behaviour of $\mathrm{Al}$ alloy/Gr. (p)composite, Elsevier, Wear, 1998, 217:167-74.

[4] Gupta AK, Saxena BK, Tiwari GP. Aluminium alloys graphite below 45 micron particle size composite: Fabrication and properties, composites, science and technology. New Delhi: New age international Ltd ; 2000, 60-65.

[5] Rohatgi PK, Guo R, Kim JK, Rao S. Wear and friction of cast aluminium-SiC-Gr Composites In: Proceedings from materials solutions 97 on wear of engineering materials, 15-18 September 1997, Indianapolis, Indiana.

[6] Hocheng.H, Yen S.B, Ishihara T, and Yen B.K, Fundamental turning characteristics of a tribology - favoured graphite/ aluminum Alloy Composite Material, Composites PartA, 1997, 28A: $883-890$.

[7] Cevdet Kaynak and Suha Boylu, Effects of SiC particulates on the fatigue behaviour of an Alalloy matrix composite. Journal of Materials and Design, Elsevier, Vol 27, Issue 9, 2006, 776-782.

[8] Srivatsan.T.S, Meslet Al-Hajri, Petraroli.M, Hotton.B, and Lam.P.C, Influence of Silicon carbide particulate reinforcement on quasi static and cyclic fatigue fracture Behavior of 6061 aluminium alloy composites, Journal of Material Science and Engineering, Elsevier, A325, 2002, 202-214.

[9] Little RE. In: Manual on statistical planning and analysis for fatigue experiments STP, vol. 588 . Philadelphia:ASTM; 1975.

[10] Lipson C, Narendra J. Sheth, statistical design and analysis of engineering experiments. Tokyo, Inc.: McGraw-Hill Kogakusha Ltd.; 1973.

[11] McDaneals, D.L. Analysis of stress-strain, fracture, and ductility behaviour of Aluminium matrix composites containing discontinuous silicon carbide reinforcement. Metall. Trans., 1985, 16A, 1105-1114.

[12] Bannantine J.A, Corner J.J, and Handrock J.L, Fundamentals of Metal Fatigue Analysis, Prentice-Hall, 1990

[13] Parida. N, S. K. Das, P. C. Gope and G. N. Mohanty, "Probability Confidence and Sample Size in Fatigue Testing", Journal of Testing and Evaluation, Vol 18, Nov 1990.

[14] Prakash Chandra Gope, "Determination of Minimum Number of Specimens in S-N Testing", Journal of Engg Materials and Technology", Vol 124/421, Oct 2002. 
[15] Metropolis N and Ulam S, "The Monte Carlo Method", Journal of the American Statistical Association, volume 44, number 247, 1949, pp. $335-341$

[16[ Fishman G.S., Monte Carlo: Concepts, Algorithms, and Applications, Springer Verlag, New York. 1995.

[17] Kahneman $D$ and Tversky A, Judgement under Uncertainty: Heuristics and Biases, ed. Cambridge University Press, 1982.

[18] Caflisch R.E, Monte Carlo and quasi-Monte Carlo methods, Acta Numerica vol. 7, Cambridge University Press, 1998, pp. 1-49.
[19] D'Agostino R.B and Stephens M.A, eds, Goodness of fit techniques, Marcel Dekker, 1986.

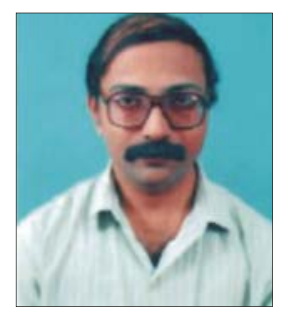

Mr. M. V. Achutha is a Research Scholar at Kuvempu University, Davangere, Karnataka and an Assistant Professor at the Department of Mechanical Engineering, National Institute of Engineering (NIE), Mysore. A postgraduate from IIT Kharagpur, his field of research is "Investigations to evaluate fatigue behaviour of hybrid metal matrix composites". 